\title{
THE INTERPLAY OF ANXIETY, LEARNING STRATEGIES AND STUDENTS' READING COMPREHENSION
}

\author{
Multazam Abubakar \\ Universitas Islam Negeri Alauddin Makassar \\ Multazam.abubakar@uin-alauddin.ac.id
}

\begin{abstract}
Anxiety is one of factors under affective domain which influences the successfulness of language learning. The aims of this study were to identify the level of anxiety experienced by the students while studying and to investigate the extent to which the students' anxiety contributes to their reading performance. The research was carried out in the second grade students of a junior high school. The design of this study was correlational research. The data were collected using three instruments: Foreign Language Reading Anxiety Scale (FLRAS), Young Learners' Language Strategy with Survey questionnaire and reading test. The data were analyzed with questionnaire frequency test and regression analysis. The result indicated that the students' anxiety level was 65.633 which indicated that they experienced high level of anxiety. To test the effect of learning strategies to as intervening variable in the relationship between anxiety as independent variable and students' reading comprehension as dependent variable, past analysis was used. Regression coefficient of direct effect, that is the correlation between anxiety and learning strategies, was 0.190 ; while indirect effect, that is the correlation between anxiety on reading comprehension through learning strategies, was -0.069 . The result implied that that learning strategies do not mediate the correlation between anxiety and reading comprehension. Therefore, the anxiety does not affect learning strategies to improve students' reading comprehension. The findings of this study might be used as input to teachers and students in an effort to create effective classroom environment.
\end{abstract}

Keywords: Anxiety, learning strategies, students' reading comprehension

\section{A. INTRODUCTION}

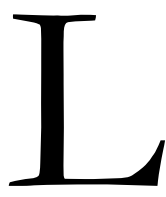

earning foreign language involves the combination of both cognitive domain and affective domain. Cognitive domain has two facets: human learning and learning styles \& strategies, while affective domain deals with personality factors and socioculture factors (Brown, 2000). Both cognitive and affective domain play important role in learning language. Learning foreign language with only considering the cognitive factor will be failed without taking affective domain into account. The process of language learning will be hindered by the affective blocking. Affective variables do not impact language learning or acquisition directly but they prevent input from reaching what Chomsky has called the Language Acquisition Device (LAD), the part of brain which is responsible for language acquisition. The input will not reach the LAD since a block that is affective filter keeps it out even if somebody gets and understands it (Krashen, 2013).

The role of affective domain in language learning has been the attention of many scholars. The have been studying the personality factors of human being that influence the successfulness of learning foreign language. There are various affecting variables that affecting 
the learning of foreign language, such as self-esteem, motivation, extroversion, inhibition, anxiety and so on. Among these affective variables, research on anxiety takes so much attention of the scholars since decades (Teimouri et al, 2019).

Almost every student who learn either second or foreign language experiences anxiety. Anxiety occurs when the students feel the apprehension and pressure to perform well in the foreign language. This anxiety causes a mental block to new information. Anxiety also makes the students worried, hard to concentrate, always feel insecure and become forgetful during learning.

Most of the previous researches come to conclusion that anxiety brings negative effect to language learning and they only consider the negative effect of anxiety (Hui-Ju Wu, 2011; Khodadady \& Khajavy, 2013; Lien, 2011; Riasati, 2011; Tsai \& Chang, 2013; Zheng \& Cheng, 2018;). Then, the meta-analysis research done by Teimouri et al. (2019) investigates 97 studies concerning anxiety and foreign language achievement published between 1985 and 2017 in 23 countries. They found that most of the studies fall in the conclusion that anxiety has negative correlation with foreign language achievement and then anxiety is best conceptualized that a negative predictor of language achievement.

However, although anxiety is commonly known as one of the personality factors that may hinder language learning, Scovel (1978) and Oxford (1999) contended that anxiety can bring positive effect to students since it is not always negative for language learning. It can bring positive effect since it is closely related to competitiveness. Furthermore, Eysenck (1979) mentions that anxious students tend to compare their personal performance to that of peers, consequences of failure, low level of confidence in performance, and excessive worry over evaluation. By recognizing all these component, the students are hope can manage the anxiety effect that they experienced.

Anxiety is believed to be closely related to learning strategies since it may affect learning strategies. Students who are aware that they experience anxiety or realize that they have problem in learning will apply certain strategies to help them improve their performance (Lucas: 2011). Learning strategies are used by students to help them understand information and solve their problems. Learning strategies are approach for students to gain information and solve their problems. Students who apply learning strategies often learn actively and finally successful in learning. Learning strategies lead them how to learn and how to use what they have learned to gain information and be successful. However, Nishitani \& Matsuda (2011) found that learners with high language anxiety are more likely to attribute failure to anxiety and less able to use of learning strategies to overcome this failure. Besides, Wu (2010) 
and Mohammadi et al. (2012) also contended that students with high level of anxiety tend to use low frequent of learning strategies.

Referring to the above studies, anxiety's effects are still important issue to be explored. There are very little researchers conclude that anxiety can bring positive effect to language learning and can improve students' performance. Besides, the context of studying anxiety experienced by young learner such as students of junior high school is rarely studied by the previous researchers since most of them only explored the anxiety phenomena suffered university and adult learners since anxiety is related with self-esteem which commonly known just experienced by adult learners. Moreover, there are also very few investigations on how anxiety affects learning strategies to improve students' performance in language learning. Thus, the context of relationship between anxiety, learning strategies and students' performance in language learning brings significant findings in the affective domain studies.

. This study the focuses on the effect of anxiety on students' performance, in this case reading comprehension through learning strategies as intervening variable. This research tried to prove that anxiety can bring positive effect to language learning. This research aimed at identifying the level of anxiety experienced by the students while studying and investigating the extent to which the students' anxiety contributes to their reading comprehension. The findings of this study are expected to contribute to the study of affective domain studies. It might also serve beneficial inputs for practitioners for classroom interaction especially English teachers and students in order to create effective EFL classroom environment.

\section{B. REVIEW OF LITERATURE}

\section{Reading anxiety}

Anxiety is feeling worried, apprehension, stressful, and uneasiness towards certain things. Eline K. Horwitz, Michael B. Horwitz and Joann Cope (1986) defined foreign anxiety as a distinct complex of self-perception, beliefs, feelings, and behaviors related to classroom language learning arising from the uniqueness of the language learning process. Foreign language anxiety can be provoked by teacher's behavior, teacher's negative evaluation, peers' negative judgments, fear of being laughed at by other students, lack of preparation, fear of making mistakes, kind of activities implemented in class, tests and classroom environment (Riasati, 2012).

Reading anxiety is a phenomenon related to, but distinct from, general foreign language anxiety (Saito et al, 1999). Reading anxiety has positive correlation with foreign language anxiety. It means that those who suffer high level of reading anxiety tend to experience high 
level of foreign language anxiety. In addition, reading anxiety, as well as foreign language anxiety, has negative correlation with students' performance. It indicates that students with high reading anxiety have lower score in their performance, vice versa.

Saito et al. (1999) stated that two aspects of foreign language reading seem to have great potential for eliciting anxiety. The first is unfamiliar scripts and writing systems. Unfamiliar writing systems deal with certain languages which have different writing systems with the reader's first language. For instance, Indonesian and English have same writing systems that are Roman alphabet, while Korean has different writing system that is hang-geul. The readers whose L1 and L2 different writing system will experience higher reading anxiety compared with those whose L1 and L2 have same writing system. They will experience anxiety as soon as they attempt to decode the scripts because they will find difficulty in processing the text. According to them, foreign language learners who are more familiar to the scripts of the target language would be less expected to experience anxiety in reading. The second is unfamiliar cultural material. The impact of unfamiliar culture material is not as immediate as unfamiliar writing systems. The readers at first will encounter the symbols, decode them into sounds and associate the sounds with the words, and then attempt to process the meaning of a text. It is at the point when the reader realizes the words he decoded do not constitute a comprehensible or logical message entity that one would expect anxiety to set in. In other words, the readers can decode the words and make meaning of the sentence. However, at some point of reading process, the reader would not make sense of the whole text due to the incomplete knowledge of the culture material underlying the text.

Furthermore, Al-Shboul et al. (2013) listed five underlying factors that provoke reading anxiety. The five underlying factors are divided into two types: text features and personal factors. Text features refer to factors that the text itself which makes the readers anxious; while the personal factors refer to the personality of the reader which makes the reading anxiety occurs. The reading anxiety factors based on text features are unknown vocabulary, unfamiliar topic and unfamiliar culture; while the personal factors are afraid of making errors and worry about reading effects.

\section{Learning strategies}

Language learning strategies are thoughts and actions, consciously selected by learners, to assist them in learning and using language in general, and in the completion of specific tasks (Cohen, 2011: 682). Learning strategies can be classified according to strategies for learning and use, strategies according to skill area, and strategies according to function. 
The first division is about strategies for learning of language materials for the first time and strategies for using the material that has been learned. It deals with communication strategies. It when learner face problem in communicating, they will apply some strategies to solve it and then to express their idea. Besides, Brown (2000) contended that the field of second language acquisition has distinguished between two types of strategy: learning strategies and communication strategies. Learning strategies relate to input such as processing, storage and retrieval. It deals with taking messages from others. Communication strategies relate to output in which they are involved how to express meaning productively and how deliver messages.

The second division is the classification according to skill area that is listening, reading, writing, speaking, vocabulary and translation. Language learners sometimes apply different strategies in learning different skills.

Finally, the last division is based on the function, namely metacognitive, cognitive, affective and social. Metacognitive strategies deal with applying certain strategies by planning what they will do, checking on progress and then evaluating their performance on a given task. Cognitive strategies involve the process in which learners go through both learning the target language (e.g., identification, grouping, retention and storage of language material) and using it (e.g., retrieval of language material, rehearsal, and comprehension or production of words, phrases and another element of target language). Social strategies deal with means employed by learners for interacting with other learners and native speakers, such as through asking questions to clarify social roles and relationships, asking for an explanation or verification and cooperating with others in order to complete tasks. Finally, affective strategies help the learners regulate their emotions, motivation and attitudes. Besides, affective strategies are used to reduce anxiety and provide self-encouragement.

Learning strategies can also be predictors in language learning successfulness (Lucas, 2011). Effective language learners are aware of strategies that they apply in language learner. They apply certain techniques to solve certain problems or tasks. It will lead them to successful learning. While, less effective learners sometimes ignore strategies in learning or they apply certain methods randomly. It may lead them to unsuccessfulness learning outcome.

\section{Reading comprehension}

Reading is one of skill in language learning. It is classified as receptive skill as well as listening. The purpose of reading is to comprehend the information gathered from the text. Westwood (2008) points out that comprehension is reading a text with full understanding draws on the readers' background experience, general knowledge, vocabulary, syntactical 
awareness and word identification skills. When the reader comprehends the text, the information will be kept and stayed longer in their mind. Successful comprehension enables readers to acquire information, to experience new worlds, to communicate successfully and to achieve academic success.

Westwood (2008) contends that reading involves two main processes: identifying words and comprehending connected text. He further mentioned that word recognition is a prerequisite for comprehension. So, in order to comprehend the text, the reader should understand the vocabularies which are used within the text. Understanding the vocabulary is the first step to comprehend the text. If the reader can understand the vocabulary, he can easily understand the meaning of the text. Meaning can only be derived if the words can be swiftly and easily recognized. Beside vocabulary, to comprehend the text, readers must use information they already possess to filter, interpret, organize and reflect upon the incoming information from the page.

Readers who are good in comprehension will understand deeply about what they have read. They can remember details of the text. They use a variety of cognitive skill as they read. They apply some strategies to comprehend the text. If readers are weak in comprehending the text, on the other hands, they will be unable to connect ideas together as they read and they remember very little of the details after they have read a text. They hardly recall the information from the passage.

Westwood (2008) further lists some causes of poor comprehension. The first is limited vocabulary knowledge. Students whose limited vocabularies tend to comprehend the text poorly since they do not understand what the text is about. Vocabulary is the heart of reading. The second is lack of fluency. The students with poor fluency also have problems in comprehend the text. The third is lack of familiarity with the subject matter. In comprehending the text, readers' background knowledge is very important so familiarity with the topic also determine the reading comprehension. The forth is difficulty level of the text (readability). The next is inadequate use of effective reading strategies. Besides, weak verbal reasoning effect the reader to have poor comprehension. Students whose problems with processing information also tend to comprehend the text poorly and the last is they have problems in recalling information after reading.

Brown (2007) suggested some strategies for reading comprehension. The first is identifying the purpose of reading. The second is using graphemic rules and patterns to aid in bottom up decoding. The third is using efficient silent reading techniques for improving fluency. The forth is skimming the text for main ideas. The fifth is scanning the text for 
specific information. The fifth is using semantic mapping of cluster. The sixth is guessing when the reader do not certain. The seventh is analyzing vocabulary. The eight is distinguishing between literal and implied meanings and the last is capitalizing on discourse marker to process relationship.

\section{METHOD}

The design of this study was correlational research in order to find out whether there is an effect of anxiety on students' learning strategies and reading comprehension. The population of this research was the second grade of a junior high school in Makassar aged between 13-15 years old. The sample of this research was selected by purposive sampling method in which it consisted of 30 students who were 16 males and 14 females with age ranged from 13 to 14 years old.

The researcher used three kinds of instruments; they are Foreign Language Reading Anxiety Scale (FLRAS), language learning strategies questionnaire that is Young Learners' Language Strategy Use Survey questionnaire, and reading test. Foreign Language Reading Anxiety Scale (FLRAS) was developed by Saito et al (1999) and commonly used to measure reading anxiety level experienced by students. The questionnaire consists of 20 statements which was translated into Bahasa Indonesia. Each 20 items were rated on a five-point Likert scale. The reliability of this test has been investigated and it shows that acceptable level of reliability with an internal consistency coefficient of $0.86(n=383)$. Meanwhile, to find out the learning strategies occupied by the students, Young Learners' Language Strategy Use Survey (YLLSUS) questionnaire used in this study. This questionnaire is developed by Cohen \& Oxford (2002) and it is commonly used to find out learning strategies of beginning or low level learners. This questionnaire originally consists of 75 items. However, since the study only focuses on reading, the questionnaire was adapted by ignoring the other skill parts. So, there were only 12 items in the questionnaire kept with the response in rating scale. Finally, to measured students' reading comprehension, a reading test which consists of 25 questions from 8 passages was used.

The data then were analysed quantitatively. The data were gathered from the calculation of the students' level of anxiety, learning strategies, reading comprehension and the correlation between the three variables which had been analysed using SPSS IBM 23. To find out the level of anxiety, the result of FLARS was converted into score. Then, based on score, students' anxiety level was classified into very low, low, average, high and very high. Next, to investigate students' reading comprehension the result of (YLLSUS) questionnaire was 
analysed. Then, the correlation between the three variables was analysed and followed by interpretation of the relationship. To test the effect of intervening variable in the relationship between independent and dependent variables path analysis was used. Path analysis is used to predict the pattern of relationship of the variables and cannot be used to determine causaleffect relationship.

\section{FINDINGS AND DISCUSSION}

The result of data analysis is as follows:

Table 1. Descriptive statistics of anxiety level experienced by the students

\begin{tabular}{llllllll}
\hline & $\mathrm{N}$ & Range & Minimum & Maximum & \multicolumn{2}{c}{ Mean } & td. Deviation \\
\cline { 2 - 7 } & Statistic & Statistic & Statistic & Statistic & Statistic & itd. Error & Statistic \\
\hline $\begin{array}{l}\text { Anxiety } \\
\text { Valid N }\end{array}$ & 30 & 32,0 & 48,0 & 80,0 & 65,633 & 14,875 & 81,473 \\
(Listwise) & 30 & & & & & & \\
\hline
\end{tabular}

Table 1 showed anxiety level that experienced by the students. The mean score of the data was 65,633 . Based on the mean score, it can be concluded that the students experienced "high" level of anxiety under study.

Table 2. Regression analysis of anxiety towards learning strategies

\begin{tabular}{|c|c|c|c|c|c|}
\hline \multirow{3}{*}{ Model } & \multirow{2}{*}{\multicolumn{2}{|c|}{$\begin{array}{c}\text { Unstandardized } \\
\text { Coefficients }\end{array}$}} & \multirow{3}{*}{$\begin{array}{c}\text { Standardized } \\
\text { Coefficients } \\
\text { Beta }\end{array}$} & \multirow{3}{*}{$\mathrm{T}$} & \multirow{3}{*}{ Sig. } \\
\hline & & & & & \\
\hline & B & Std. Error & & & \\
\hline 1 (Constant) & 49,461 & 7,603 & & 6,505 & 0,000 \\
\hline X1: Anxiety & 0,359 & 0,115 & 0,508 & 3,123 & 0,004 \\
\hline
\end{tabular}

a. Dependent Variable : X2 : Learning

Table 2 showed that the regression coefficient of anxiety towards learning strategies is 0.508. It indicates that anxiety is positive correlated and significant towards learning strategies so the high level of anxiety increases students' learning strategies.

Table 3. Multiple regression analysis of anxiety and learning strategies toward reading comprehension

\begin{tabular}{|c|c|c|c|c|c|}
\hline \multirow{3}{*}{ Model } & \multirow{2}{*}{\multicolumn{2}{|c|}{$\begin{array}{c}\text { Unstandardized } \\
\text { Coefficients }\end{array}$}} & \multirow{2}{*}{$\begin{array}{l}\text { Standardized } \\
\text { Coefficients }\end{array}$} & \multirow{3}{*}{$\mathrm{T}$} & \multirow{3}{*}{ Sig. } \\
\hline & & & & & \\
\hline & B & Std. Error & Beta & & \\
\hline (Constant) & 63,446 & 30,661 & & 2,069 & 0,048 \\
\hline $\mathrm{X} 1$ & 0,293 & 0,340 & 0,190 & 0,862 & 0,396 \\
\hline $\mathrm{X} 2$ & $-0,299$ & 0,481 & 0,137 & $-0,622$ & 0,539 \\
\hline
\end{tabular}

a. Dependent Variable : Y

Table 3 showed that he regression coefficient of anxiety towards reading comprehension is 0.190 . It indicates that anxiety is positive correlated but not significant towards reading comprehension. Besides, the regression coefficient of learning strategies 
towards reading comprehension is -0.137 . It indicates that learning strategies are negative correlated and not significant toward reading comprehension. Negative correlation means that a relationship between two variables in which one variable increases as the other variable decreases and vice versa.

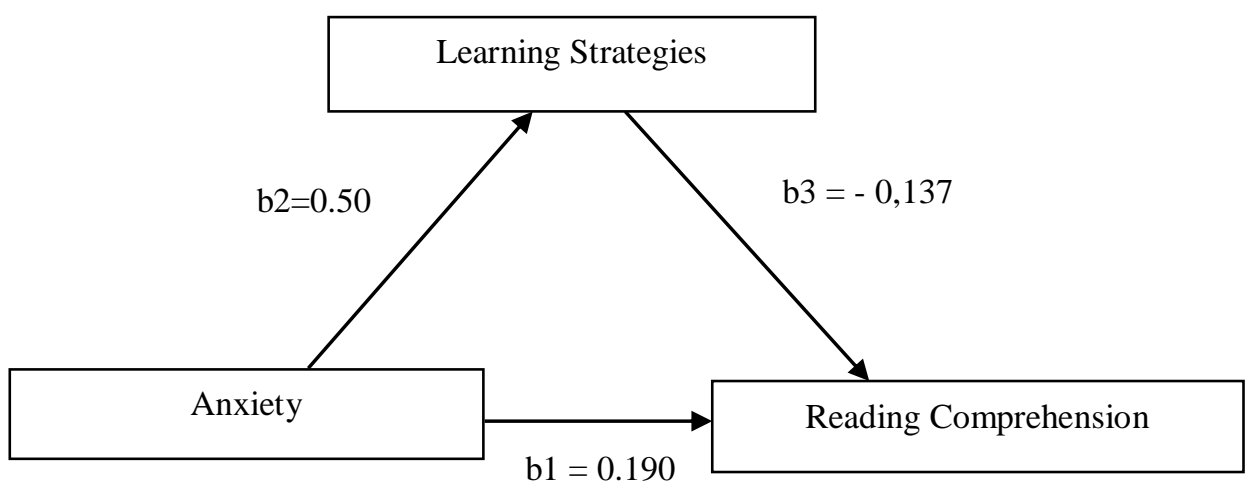

Figure 1. Intervening analysis of anxiety and learning strategies toward reading comprehension

In order to analyze the effect of anxiety towards learning strategies and its implication in students' reading comprehension, intervening analysis is done. Path analysis is done by calculating direct and indirect effect between anxiety and reading comprehension. Figure 1 showed the path analysis of intervening variable. The relationship of anxiety and reading comprehension is called direct effect and the regression coefficient of between the two variables which is symbolized by $b 1$ is 0.190 . The regression coefficient of anxiety towards learning strategies which is symbolized by $b 2$ is 0.508 and the regression coefficient of learning strategies toward reading comprehension which is symbolized by $b 3$ is -0.137 . So, the indirect effect of anxiety towards reading comprehension by employing learning strategies can be found by calculating b2 $\mathrm{x}$ b3 that is $0.508 \times-0.137=-0.069$. Since b1 $(0.190)$ is higher than b2 x b3 (-0.069) it can be concluded that anxiety affects reading comprehension directly and learning strategies as intervening variable has no effect of the relationship between anxiety and reading comprehension. So, learning strategies do not mediate the relationship between anxiety and reading comprehension.

Based on the analysis result, anxiety and reading comprehension have positive correlation. It means that if the anxiety level is high, students' reading comprehension is also high. This finding is contradicted with Krashen's affective filter theory (2013), which strongly stated that anxiety and students' performance have negative correlation and it can hinder language learning process. In addition, the findings of this research also contradicted with Humphries (2011), which also stated that language anxiety was a substantially negative impact on performance and it hindered learners' progress and proficiency in target language. 
Unlike researches that mentioned above, the findings of this study is in line with Trang et al (2012) who found that anxiety effect could be managed so it would not bring negative effect. This finding also support the theory of Scovel (1978) and Oxford (1999) who contends that anxiety can bring positive effect to language learning. In early study, Eysenck (1979) mentions that anxious students tend to compare their personal performance to that of peers, consequences of failure, low level of confidence in performance, and excessive worry over evaluation. By recognizing all these component, the students are managed the anxiety effect that they experienced. They compared their personal performance with their peers, and having realized that the other friends have better performance, the students feel sense of competitiveness. They will not lead themselves to have the lowest score so they make efforts to be the best. They also realized the consequences of failure; they would feel shy with teacher and classmate judgement if they are fail or got low score. This condition leads them to do the best.

The effect of anxiety towards reading with learning strategies as intervening variable is the center of this study. The findings of the research imply that learning strategies do not mediate anxiety and reading comprehension. It is proved by the value of direct effect and indirect effect. Based on intervening analysis, the value of direct effect is higher than the value of indirect effect. It means that anxiety do not affect reading comprehension through learning strategies. Anxiety has positive correlation with learning strategies. It means that if anxiety is high, learning strategies applied will be high. However, the regression between learning strategies and reading comprehension shows that both variables have negative correlation. It means that if learning strategies are high, reading comprehension will be poor. However, in intervening analysis it is found that learning strategies do not affect the correlation between anxiety and reading comprehension. So, it is not learning strategies that affect anxiety and reading comprehension, but other factors. This result is in line with Nishitani \& Matsuda (2011), who found that learners with high language anxiety are more likely to attribute failure to anxiety and less able to use of learning strategies to overcome this failure.

To sum up, anxiety negatively affects learner's confidence and self-esteem. So, having realized that they are anxious, the students become aware of themselves. The students feel the sense of competitiveness so when they realize that they are anxious, their motivation is high and it improve their reading comprehension. Students who are realize that they are anxious motivate themselves to study and finally they achieve successfulness in study. Besides, due to the student's level is junior high school, so they study the vocabularies which are used commonly in discourse. So, it was quite easy for them to guess the meaning. Furthermore, the 
topic of the text is also very familiar, that is concerning daily life; thus, the did not encounter any obstacles in comprehending the texts and answering the questions followed. Finally, the use of learning strategies in comprehending the text is not required in this condition, that is in the context of junior high school students.

\section{E. CONCLUSION}

It can be concluded that the students experience high level of anxiety while studying. Meanwhile, it also found that learning strategies do not mediate the correlation between anxiety and reading comprehension. So, anxiety does not affect learning strategies to improve students' reading comprehension in the context of junior high school students. The findings of this study also show that anxiety improves reading comprehension through students' confidence and self-esteem. The students feel the sense of competitiveness so when they realize that they are anxious, their motivation is high and it improve their reading comprehension.

The findings of this study can become input for practitioners of the EFL classroom interaction, especially English teachers and students, about how they should behave in the classroom in order to reach positive effect of anxiety. Having realized that students experience anxiety while studying, the teacher is supposed to help the students to manage their anxiety effect. The teacher should motivate the students so they can feel the sense of competitiveness and then feel anxious to give the best performance and also they make effort to get the highest score. In other side, the students who experience anxiety will not feel down as well as demotivated, thus they can motivate themselves to be the best. However, further researches need to be conducted in terms of learning strategies used by junior high school students which are influenced by anxiety in productive skills, they are speaking and writing anxiety, since the current research only focused on one of receptive skills, that is reading skill.

\section{REFERENCES}

Al-Shboul, M. M. et al. (2013). Foreign Language Reading Anxiety in Jordanian EFL Context: A Qualitative Study. English Language Teaching; Vol. 6, No. 6.

Brown H. D. (2000). Principles of Language Learning and Teaching (Forth Edition). New York: Pearson Education.

Chen I. J. \& Chang C. C. (2009). Cognitive Load Theory: An Empirical Study of Anxiety and Task Performance in Language Learning. Electronic Journal of Research in Educational Psychology, 7(2): 726-729. 
Cohen, Andrew D. and Oxford, Rebecca L. 2002. Young Learners' Language Strategy Use Survey. Styles and Strategies-Based Instruction: A Teachers' Guide pp 75-78.

Eysenck, M. W. (1979). Anxiety, learning, and memory: A reconceptualization. Journal of Research in Personality, 13, 363-385.

Hui-Ju W. (2011). Anxiety and Reading Comprehension Performance in English as a Foreign Language. Asian EFL Journal, 13(2).

Humphries R. (2011). Language Anxiety in International Students: How can it be overcome?. Griffith Working Papers in Pragmatics and Intercultural Communication, 4:65-77.

Khodady E. \& Khajavy G. H. (2013). Exploring the Role of Anxiety and Motivation in Foreign Language Achievement: A Structural Equation Modeling Approach. Porta Linguarum, 20:268-269.

Krashen S. (2013). Second Language Acquisition: Theory, Application and Some Conjectures. Mexico City: Cambridge University Press.

Lien H. Y. (2011). EFL Learners' Reading Strategy Used in Relation to Reading Anxiety. Language Education in ASLA, 2(2):199-212.

Mohammadi, Ebrahim Ghorban et al. The Relationship between Foreign Language Anxiety and language Learning Strategies among University Students. Theory and Practice in Language Studies, Vol. 3, No. 4, pp. 637-646, April 2013.

Nishitani M. \& Matsuda T. (2011). The Relationship between Language Anxiety, Interpretation of Anxiety, Intrinsic Motivation and the Use of Learning Strategies. US-China Education Revien B3:438-446.

Oxford, R. L. (1999). Anxiety and the Language Learners: New Insights. In Arnold Jane 1999. Cambridge University Press: 58-67.

Riasati M. J. (2011). Language Learning Anxiety from EFL Learners' Perspective. Middle-East Journal of Scientific research, 7(6): 907-914.

Saito, Y. , Horwitz, E. K., \& Garza, T. J. (1999). Foreign Language Reading Anxiety. The Modern Language Journal, 83 (2), 202-218.

Scovel, T. (1978). The Effect of Affect on Foreign Language Learning: A Review of the Anxiety Research. Language Learning : A Journal of Research in Language Studies. Volume 28 Issue 1.

Teimouri, Yasser \& Julia Goetze. (2019). Second Language Anxiety and Achievement: A Meta-Analysis. Studies in Second Language Acquisition Vol. 41 issue 2, 363-387. Doi: $10.1017 / \mathrm{S} 0272263118000311$ 
Multazam Abubakar, The Interplay Of Anxiety...

Trang T. T. et al. (2012). Foreign Language Anxiety and Its Effect on Students; Determination to Study English: To Abandon or not To Abandon?. TESOL in Context Special Edition S3.

Tsai C. \& Chang I. (2013). The Study of Motivation and Anxiety of English Learning of Students at a Taiwan Technical University. International Journal of English Language Teaching, 1(1):24-41.

Westwood, Peter. (2008). What Teachers Need to Know about Reading and Writing Difficulties. Victoria: ACER Press.

Wu, Kun-Huei. (2010). The Relationship between Language Learners' Anxiety and Learning Strategy in the CLT Classrooms. International Education Studies, Vol. 3, No. 1, pp. 174-191.

Zheng \& Cheng. (2018). How does anxiety influence language performance? From the perspectives of foreign language classroom anxiety and cognitive test anxiety. Language Testing in Asia 8:13. https://doi.org/10.1186/s40468-018-0065-4 